\title{
Infantile Tremor Syndrome Presenting as Stroke
}

\author{
Vykuntaraju K. Gowda' ${ }^{1} \cdot$ Navya K. Umesh ${ }^{2} \cdot$ Varunvenkat M. Srinivasan $^{2} \cdot$ Maya Bhat $^{3}$
}

Received: 8 August 2021 / Accepted: 12 October 2021 / Published online: 26 October 2021

(c) Dr. K C Chaudhuri Foundation 2021

To the Editor: Infantile tremor syndrome (ITS) is characterized by pallor, developmental delay, tremors, skin and hair changes [1]. We report a child of ITS presenting as stroke.

A 1-y-old boy presented with left upper and lower limb weakness of $3 \mathrm{~d}$ following loose stools. The child was on exclusive breast-feeding and attained only head control and social smile. Following loose stools, there was loss of social smile and neck control. On examination, weighed $8.5 \mathrm{~kg}(0$ to $-2 z$ score), length $67 \mathrm{~cm} \mathrm{(}-2$ to $-3 z$ score), and head circumference $42.5 \mathrm{~cm}(-2$ to $-3 z$ score $)$, lethargic with severe pallor, sparse, hypopigmented hair, and knuckle hyperpigmentation, power (medical research council grading) of $2 / 5$ on the left side, and tremors.

On investigation, severe megaloblastic anemia (hemoglobin - $2.9 \mathrm{~g} / \mathrm{dL}$ ), low serum vitamin B12 levels $65 \mathrm{pg} / \mathrm{mL}$ (normal - 200-300 pg/mL), and elevated serum homocysteine level $68 \mu \mathrm{mol} / \mathrm{L}$ (normal - 3-15) were noted. Mother's investigations showed megaloblastic anemia (hemoglobin $-8 \mathrm{~g} / \mathrm{dL}$ ), with low B12 level $(120 \mathrm{pg} / \mathrm{mL})$. MRI of the brain showed T2W hyperintensities in right globus pallidus and crus cerebri and DWI and ADC maps show diffusion restriction in the right globus pallidus and crus cerebri. Arterial blood gas, tandem mass spectrometry, gas chromatography-mass spectrometry, and exome sequencing were normal. Stroke was attributed to transient hyperhomocysteinemia secondary to vitamin B12 deficiency. With intravenous vitamin B12 $1000 \mathrm{mcg}$, improvement in development, left-sided power, and hemoglobin increased to $10.5 \mathrm{~g} / \mathrm{dL}$ and homocysteine level decreased to $12 \mu \mathrm{mol} / \mathrm{L}$.

Here we present a case of ITS with stroke following acute gastroenteritis. We considered stroke due to inborn errors

Vykuntaraju K. Gowda

drknvraju08@gmail.com

1 Department of Pediatric Neurology, Indira Gandhi Institute of Child Health, Bengaluru, Karnataka 560029, India

2 Department of Pediatrics, Indira Gandhi Institute of Child Health, Bengaluru, Karnataka, India

3 Department of Neuroradiology, National Institute of Mental Health and Neurosciences (NIMHANS), Bengaluru,

Karnataka, India of cobalamin metabolism; abnormalities in homocysteine metabolism, organic acidemias were excluded. The elevated homocysteine can cause increased coagulation, increased cholesterol synthesis, and oxidative stress with reduced apolipoprotein A1 synthesis which leads to endothelial injury $[2,3]$. In this case, we postulate the elevated homocysteine as the cause of stroke, that reversed after Vitamin B12 administration. ITS can present as stoke, in addition to classical presentation of developmental delay, tremors, and anemia.

\section{Declarations}

Conflict of Interest None.

\section{References}

1. Gowda VK, Kolli V, Benakappa A, Srinivasan VM, Shivappa SK, Benakappa N. Case series of infantile tremor syndrome in tertiary care pediatric centre from Southern India. J Trop Pediatr. 2018;64:284-8.

2. Alehan F, Saygi S, Gedik S, Kayahan Ulu EM. Stroke in early childhood due to homocystinuria. Pediatr Neurol. 2010;43:294-6.

3. Rezazadeh A, Oveisgharan S, Shahidi G, Naghdi RA. Case report of homocystinuria with dystonia and stroke. Child Neurol Open. 2014;1:2329048X14545870.

Publisher's Note Springer Nature remains neutral with regard to jurisdictional claims in published maps and institutional affiliations. 